\title{
Drug-use patterns and severe adverse events with disease-modifying drugs in patients with multiple sclerosis: a cohort study based on German claims data
}

\author{
Alexandra Simbrich' \\ Jasmine Thibaut ${ }^{\prime}$ \\ Laura Khil ${ }^{1,2}$ \\ Klaus Berger' \\ Oliver Riedel ${ }^{3}$ \\ Niklas Schmedt ${ }^{3,4}$ \\ 'Institute of Epidemiology and Social \\ Medicine, University of Münster, 48I49 \\ Münster, Germany; ${ }^{2}$ Cancer Registry \\ North Rhine-Westphalia, 4480I, \\ Bochum, Germany; ${ }^{3}$ Department of \\ Clinical Epidemiology, Leibniz Institute \\ for Prevention Research and \\ Epidemiology - BIPS, 28359 Bremen, \\ Germany; ${ }^{4}$ InGef - Institute for Applied \\ Health Research Berlin GmbH, I0II7 \\ Berlin, Germany
}

This article was published in the following Dove Press journal:

Neuropsychiatric Disease and Treatment

\begin{abstract}
Purpose: To describe drug-use patterns in patients with multiple sclerosis (MS) using disease-modifying drugs (DMDs) and to estimate the incidence of severe adverse events (SAEs) of treatment.

Methods: We conducted a cohort study within the German Pharmacoepidemiological Research Database between January 1, 2006 and December 31, 2013. MS patients on DMDs were described in terms of clinical characteristics and drug-use patterns. Next, we assessed the incidence of AEs in new users of fingolimod, natalizumab, glatiramer acetate, and IFN $\beta_{1 \mathrm{a}}$.

Results: Among approximately 11 million insured members of German Statutory Health Insurance, the DMD-user cohort comprised 15,377 patients with MS, with a mean age of 39.6 years and $68 \%$ females. Nearly half of all DMD users had a diagnosis of depression, with prevalence ranging from $40.1 \%$ for IFN $\beta_{1 \mathrm{a}}$ to $62.3 \%$ for immunoglobulins. The overall rate of MS relapses per patient and year was 0.34 (95\% CI 0.33-0.34). During an average follow-up of 1,650 days, the majority (42.4\%) of MS patients were adherent to DMD treatment ("continuous single users"), followed by patients interrupting treatment (39.5\%, "interrupters"). Switch of DMD treatment $(11.9 \%)$ was less frequent, and only $5.6 \%$ discontinued treatment. Treatment discontinuation was most common in users of natalizumab (7.5\%) and IFN $\beta_{1 b}(7.0 \%)$. The most frequent SAE was hospitalization for depression, followed by any infectious disease and any malignancy. The incidence rate of all adverse events did not significantly differ across different DMDs.

Conclusion: Treatment discontinuation with DMDs and treatment switch were rare. Causes of rather frequent DMD-treatment interruption have to be evaluated in further studies based on primary data collection. Active safety monitoring of new DMDs based on claims data requires large data sets to detect rare AEs and availability of up-to-date data.
\end{abstract}

Keywords: multiple sclerosis, drug-use patterns, adverse events, claims data, diseasemodifying drugs

\section{Introduction}

Multiple sclerosis (MS) is a chronic inflammatory disease of the central nervous system associated with several comorbidities, contributing considerably to impair ment and disability in early adulthood. ${ }^{1}$

Increase has been reported for Europe and also for Germany, leading to a growing burden of health care-related costs for the German health-care system. ${ }^{2,3}$
Leibniz Institute for Prevention Research and Epidemiology - BIPS, Achterstr. 30

Bremen 28359, Germany

Tel +4942I2 I85 6833

Fax +4942121856941

Email riedel@leibniz-bips.de 
No curative treatment for MS exists, and diseasemodifying drugs (DMDs) are the standard treatment to reduce the number and severity of relapses and to decelerate disease progression. IFN $\beta$ and glatiramer acetate were the first licensed DMDs, but several new drugs have been approved in the past decade. ${ }^{4}$ Interferons and glatiramer acetate are considered first-line treatment in patients with clinical isolated syndrome not fulfilling criteria for MS and patients with mild-moderate relapsing-remitting MS. ${ }^{5}$ Other DMDs, such as natalizumab, fingolimod, and alemtuzumab, are recommended for patients with insufficient response to first-line treatments or those with high disease activity. ${ }^{6-10}$

Although the newer drugs are highly efficacious, use of these DMDs requires careful patient monitoring, due to a higher risk of severe adverse events. ${ }^{4,5}$ For instance, natalizumab and fingolimod have been associated with progressive multifocal leukoencephalopathy (PML), ${ }^{11,12}$ a demyelinating and potentially fatal disease of the central nervous system. ${ }^{13}$ Data from disease registries are crucial to monitor drug use and safety profiles of novel treatments in MS in the real-world setting. ${ }^{14}$ Since the implementation of registries is very cost-intensive and timeconsuming, claims data represent another valuable data source to complement data from disease registries. ${ }^{15,16}$

Data on drug-use patterns of DMDs in clinical practice and the incidence of serious adverse events from Germany is scarce. Available evidence is mostly restricted to studies of individual drugs ${ }^{17-23}$ or is almost outdated and does not cover newer drugs, such as natalizumab or fingolimod. ${ }^{24}$ Therefore, the objective of this study was to describe the clinical characteristics and drug-use patterns of MS patients using DMDs and to estimate the incidence of severe adverse events in DMD users.

\section{Methods}

\section{Data source}

The data source for this study was the German Pharmacoepidemiological Research Database (GePaRD), which has been described in detail elsewhere. ${ }^{25,26} \mathrm{GePaRD}$ is based on claims data from four statutory health-insurance providers in Germany, and currently includes information on more than 20 million persons who have been insured with one of the participating providers since 2004 or later. Per data year, there is information on approximately $17 \%$ of the general population, and all geographical regions of Germany are represented. For this study, we used a subsample of three German statutory health insurances (SHI), including data of approximately 11 million individuals to analyze clinical characteristics and drug-use patterns of DMDs among those with MS. Adverse events were investigated based on the complete database.

In brief, GePaRD contains demographic characteristics, including age and sex of the insured persons, data on hospitalizations, ambulatory care, and outpatient drug prescriptions. Via linkage to a pharmaceutical reference database, further information on Anatomical Therapeutic Chemical classification code, defined daily dose (DDD), and packing size can be obtained for each drug prescription. Drugs purchased over the counter and in-hospital medications are not included, with a few exceptions of expensive drug treatments administered in hospital (eg, alemtuzumab, rituximab, and natalizumab). All diagnoses in hospital and ambulatory care are coded according to the German Modification of the ICD10 (ICD10-GM).

\section{Study population}

We conducted a cohort study to investigate the clinical characteristics and drug-use patterns of DMDs in patients with MS and to estimate the incidence rate of severe adverse events in new users of fingolimod, natalizumab, glatiramer acetate, and IFN $\beta_{1 \mathrm{a}}$. The study period started on January 1, 2006 and ended on December 31, 2013 (depending on the availability of data of the individual SHI). Data from January 1, 2004 through December 31, 2005 were used only for assessment of exclusion criteria, comorbidity, and comedications.

In the first step, we selected a cohort to investigate clinical characteristics and drug-use patterns of DMD users with MS (DMD-user cohort). Individuals were eligible for the DMD-user cohort, if they had had at least one outpatient dispensation or in-hospital administration of a DMD, continuous insurance of at least 2 years during the study period (baseline period), at least one main hospital-discharge diagnosis or one confirmed outpatient diagnosis of MS (ICD10-GM G35) within the 365 days preceding the DMD dispensation, and valid information on age and sex. Cohort entry was defined as the date of the first outpatient DMD dispensation or inhospital administration, if all inclusion criteria were fulfilled. Patients were then followed until SHI disenrollment, death, or December 31, 2013, whichever occurred first.

For assessment of adverse events, a subgroup of new users of fingolimod, natalizumab, glatiramer acetate, and 
IFN $\beta_{1 \mathrm{a}}$ (new-user subcohort) was selected from the DMD cohort and enriched with additional data from a fourth SHI. Patients were eligible for analysis only if they had not had an outpatient dispensation or in-hospital administration of a DMD in the baseline period. Follow-up accrued from the date of the first outpatient DMD dispensation or in-hospital administration until SHI disenrollment, death, treatment discontinuation of the DMD, the end of the study period, or occurrence of an adverse event, whichever occurred first.

\section{Exposure definition}

As exposure, outpatient dispensations of glatiramer actetate (L03AX13), IFN $\beta_{1 \mathrm{a}}$ (L03AB07), IFN $\beta_{1 \mathrm{~b}}$ (L03AB08), alemtuzumab (L01XC04, L04AA34), fingolimod (L04AA27), natalizumab (L04AA23), azathioprine (L04AX01), immunoglobulins (J06BA01, J06BA02, L04AA03, L04AA04), mitoxantrone (L01DB07), methotrexate (L01BA01, L04AX03), rituximab (L01XC02), and cyclophosphamide (L01AA01) and in-hospital administration of alemtuzumab, rituximab, and natalizumab were assessed. Alemtuzumab, methotrexate, and rituximab were not approved for MS during the study period, but were assessed as potential rescue therapy. As data were available only until 2013, drugs approved later, such as teriflunomide, dimethyl fumarate, and cladribine, could not be examined. All patients in the DMD-user cohort and the new-user subcohort were classified as users of a specific DMD based on the prescription leading to cohort entry (index DMD). Patients receiving two or more drugs at the date of cohort entry were considered a separate group. All patients in the DMD-user cohort were also categorized as prevalent or new users.

Since GePaRD does not provide the prescribed duration of each drug dispensation, the supply had to be estimated to construct DMD-treatment episodes. This was done based on the DDD for each outpatient dispensation. For in-hospital administrations, we estimated a supply of 365 days for alemtuzumab, 30 days for natalizumab, and 182 days for rituximab. Additional supply of $100 \%$ was added to calculate the end of supply for each dispensation and account for dosing variations and poor adherence. To be considered for the same drug-specific treatment episode, the calculated end of supply $(\times$ DDDs $+100 \%)$ of a previous prescription had to overlap the dispensation date of the following prescription of the index DMD. Otherwise, the calculated end of supply of the last dispensation was considered the end of treatment.

\section{Clinical characteristics}

At baseline, comorbidities and comedications were assessed based onmainhospital-discharge diagnoses and confirmed outpatient diagnoses. Detailed definitions of all variables are available in Table $\mathrm{S} 1$ and $\mathrm{S} 2$. In addition to drugs used for chronic diseases and to treat symptoms of MS, comedication also included outpatient dispensations or in-hospital administration of DMDs and treatment of relapses with parenterally administered methylprednisolone. For the latter, we calculated the number of prescribed DDDs per day during follow-up as a proxy for the severity of a relapse. In addition, MS patients receiving in-hospital therapeutic plasmapheresis and immunoadsorption for treatment-refractory relapses were identified.

The number of relapses per person-year of follow-up under treatment with each DMD was calculated based on an outpatient dispensation of parenteral methylprednisolone, hospitalization with a main discharge diagnosis of MS with relapse (ICD10-GM codes G35.01, G35.11, G35.21, and G35.31), or hospitalization with a claim for in-hospital therapeutic plasmapheresis. To be considered a new relapse, a minimum gap of at least 30 days was required between all these events described. The number of hospitalizations and the number of different dispensed drugs were assessed as indicators of overall health status within the 2 years prior to cohort entry.

\section{Data analysis}

The DMD cohort was categorized with respect to sex, age at cohort entry, follow-up time, comorbidities, and comedication. In addition, the percentage of new users was calculated.

After construction of DMD-specific treatment episodes, the number of different individual DMDs used during cohort times and all DMD users were categorized into one of the following mutually exclusive groups regarding their drug-use patterns: 1) discontinuation of any DMD, ie, no outpatient dispensation or in-hospital administration of any DMD for 182 days after the end of the index treatment episode; 2) switch to another DMD, ie, if a treatment episode with another DMD started within the dispensation date of the last dispensation of the index DMD and 182 days after the end of the index treatment episode; 3) multiple use of two or more DMDs, ie, if the patient received a dispensation of another DMD before or on the same day of the last dispensation within the index 
treatment episode or if the patient received a dispensation of two or more DMDs at cohort entry; 4) interruption of treatment with the index DMD, ie, if the start date of a new treatment episode with the index DMD was within 182 days after the index treatment episode; and 5) continuous single use of the index DMD, ie, if the index DMD was used continuously until the end of follow-up.

In the new-user subcohort, the crude incidence rate of each adverse event per 100,000 person-years was calculated with corresponding 95\% CIs. Adverse events were ascertained based on main hospital-discharge diagnoses after cohort entry, and included cardiac arrhythmias and conduction disorders (excluding atrial fibrillation), myocardial infarction, stroke, eye disorders, PML, any infectious disease, lymphoma, any malignancy, anxiety disorders, depression, and allcause mortality (Tables S1). Patients with a previous outpatient or inpatient diagnosis of the outcome in the baseline period were excluded. For eye disorders, PML, any infectious disease, anxiety disorders, and depression-only patients with hospitalization for the event in the baseline period were excluded. In a sensitivity analysis, patients were not censored at treatment discontinuation of the DMD for the calculation of incidence rates to account for possible latency periods and delayed occurrence of some outcomes (eg, PML and malignancies).

\section{Ethics}

In Germany, the utilization of health-insurance data for scientific research is regulated by the Code of Social Law. All health-insurance providers involved and the German Federal (Social) Insurance Office and Senator for Science, Health, and Consumer Protection in Bremen approved the use of GePaRD data for this study. Informed consent for studies based on GePaRD is not required by law, and according to the Ethics Committee of the University of Bremen, these studies are exempt from institutional review-board review.

\section{Results}

The DMD-user cohort comprised 15,377 patients with MS. The most frequent index drug was IFN $\beta_{1 a}(41.4 \%)$ followed by glatiramer acetate $(26.6 \%), \operatorname{IFN}_{1 \mathrm{~b}}(18.8 \%)$, azathioprine (6.3\%), natalizumab (2.9\%), immunoglobulins (1.7\%), and fingolimod (1.4\%) (Table 1). Results for users of methotrexate $(n=52)$, rituximab $(n=47)$, mitoxantrone $(n=35)$, cyclophosphamide $(n=15)$, alemtuzumab $(n=0)$, and patients with more than one DMD at cohort entry are not further displayed, due to the low number of events. The mean follow-up was 1,650 days (SD 996 days), and 1.7\% of all DMD users died during follow-up. Mean follow-up duration differed among the different DMD users, with the longest for azathioprine (1993.3 days) and the shortest for fingolimod (510.6 days; Table S3).

\section{Demographic and clinical characteristics}

Table 1 displays demographic and clinical characteristics of DMD users with MS. More information is available in Table S3. The mean age of the DMD-user cohort was 39.6 years (SD 10.5 years) and did not substantially differ among the different DMD groups: it ranged from 36.3 years (SD 9.5 years) for natalizumab to 40.6 years (SD 10.7) for immunoglobulins. Only MS patients treated with azathioprine were substantially older, with a mean age of 48.2 years (SD 11.3 years). In total, 68\% were female, and the female:male ratio was approximately $2: 1$, except for immunoglobulins and fingolimod: $84.8 \%$ and $74.5 \%$ for females, respectively.

With regard to comorbidities, other autoimmune disorders, such as rheumatic arthritis/collagen vascular disease $(5.8 \%)$ and inflammatory bowel diseases $(10.7 \%)$ were frequently observed. Inflammatory bowel diseaseswere most common in users of azathioprine (14.8\%), followed by natalizumab users (12.4\%). Nearly half of all included patients with MS had a diagnosis of depression, with a prevalence range of $40.1 \%$ in IFN $\beta_{1 \text { a }}$ users to $62.3 \%$ in those receiving immunoglobulin treatment. Complications of MS, such as muscle spasticity, fatigue, and bladder dysfunction, were most often observed in MS patients treated with fingolimod, followed by azathioprine and natalizumab. The mean rate of MS relapses per patient per year was 0.34 (95\% CI 0.33-0.34) and was similar for all DMDs, except for patients receiving natalizumab, with 0.50 (95\% CI 0.46-0.53) and immunoglobulins, with 0.46 (95\% CI 0.42-0.50).

With regard to comedication, opioids were most prescribed in users of immunoglobulins $(14.0 \%)$ and those on azathioprine (13.7\%). In contrast, nonsteroidal antiinflammatory drug(NSAID)use was most often seen in users of fingolimod (50.5\%). MS-specific treatment with fampridin, as well as plasmapheresis and immunoadsorption, was rarely used overall and most common in users of natalizumab and fingolimod. Similarly, the proportion of DMD users previously treated with methylprednisolone 


\begin{tabular}{|c|c|c|c|}
\hline 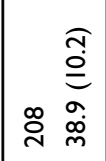 & 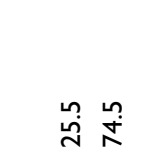 & 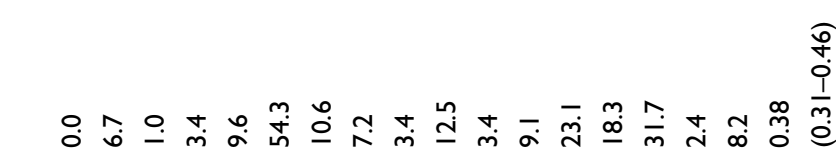 & 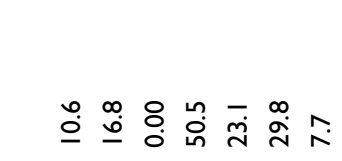 \\
\hline 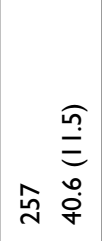 & $\stackrel{\sim}{\underline{\underline{n}}} \stackrel{\infty}{\infty}$ & 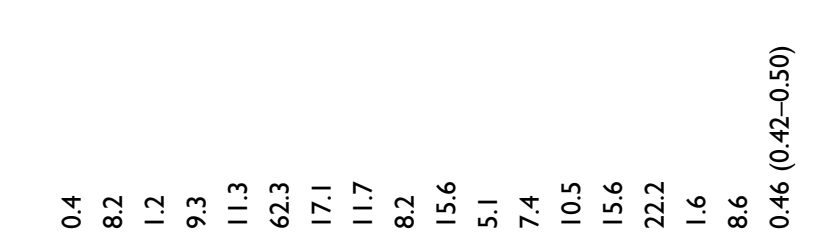 & 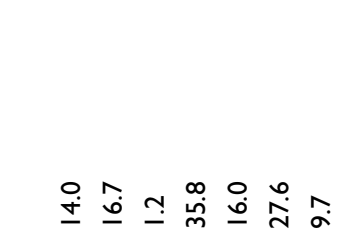 \\
\hline 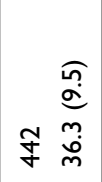 & $\hat{m} \underset{m}{m}$ & 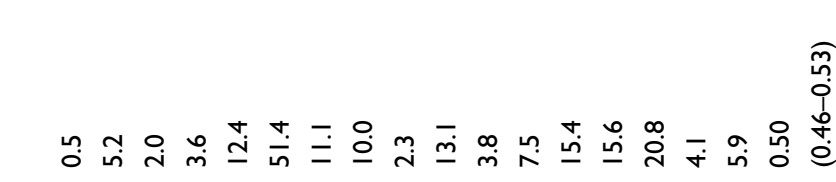 & 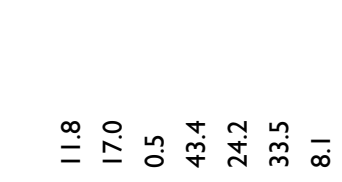 \\
\hline 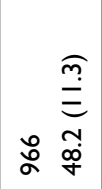 & 离 & 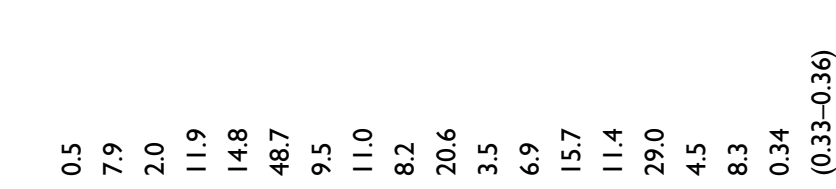 & 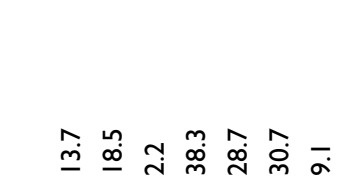 \\
\hline 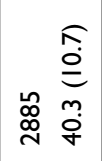 & 望 & 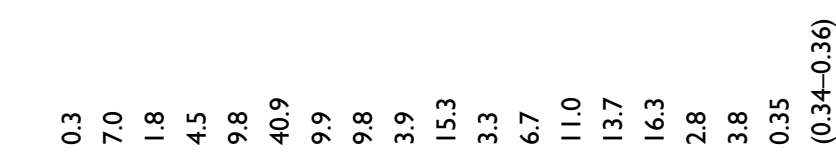 & 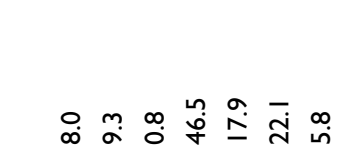 \\
\hline 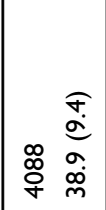 & $\overline{\text { নे }}$ & 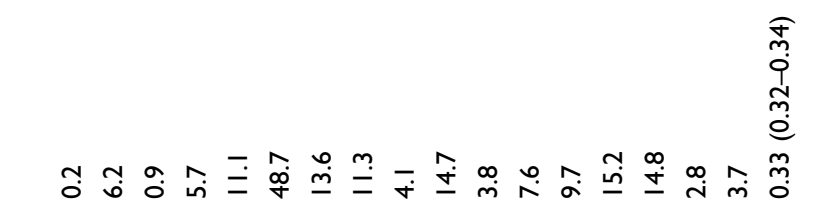 & 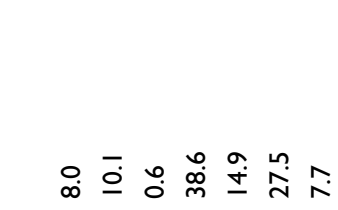 \\
\hline 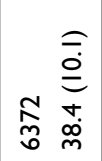 & $\frac{\infty}{m} \underset{m}{\infty}$ & 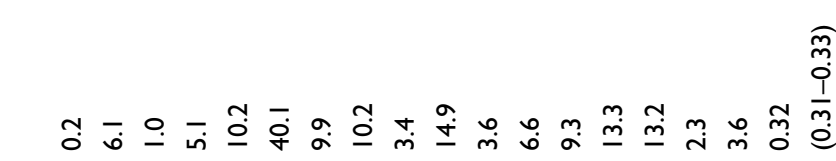 & 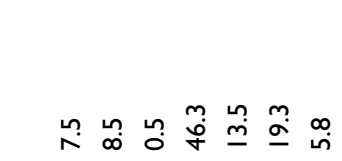 \\
\hline 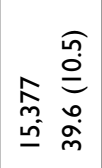 & $\stackrel{\substack{0 \\
m}}{\stackrel{\sigma}{\infty}}$ & 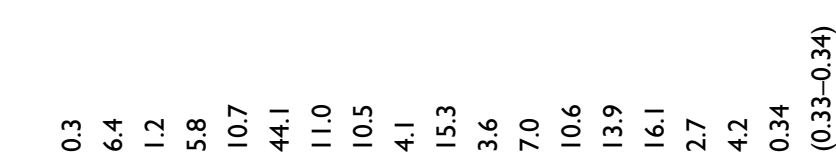 & 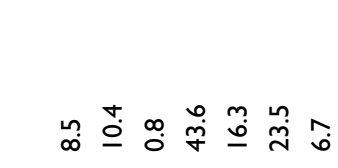 \\
\hline 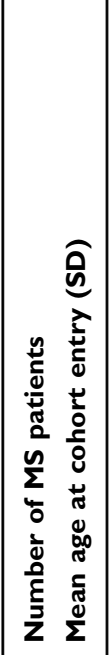 & 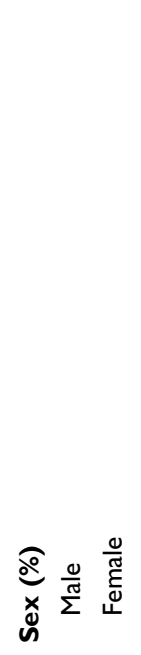 & 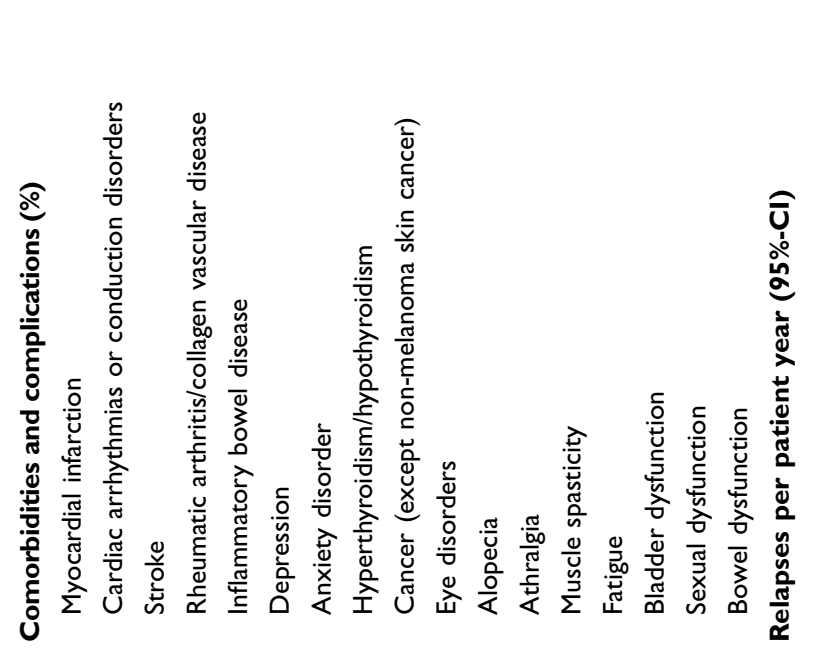 & 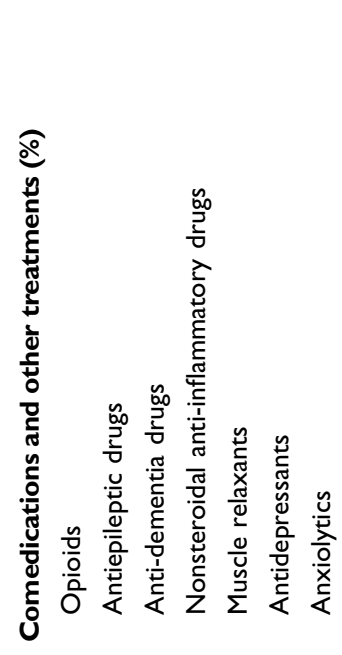 \\
\hline
\end{tabular}




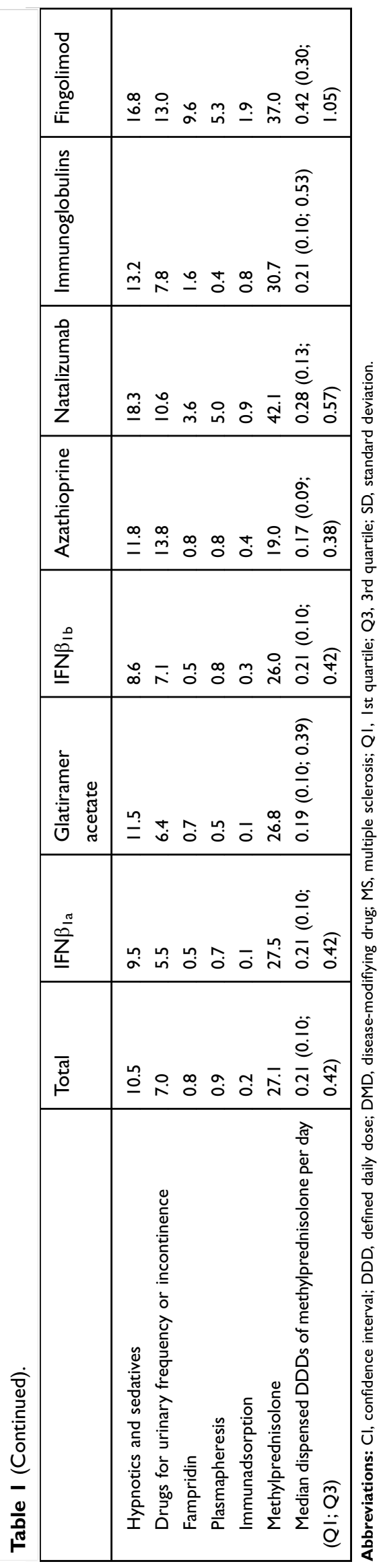

and the median number of DDDsdispensedduring followup was substantially higher for users of natalizumab and fingolimod compared to other DMDs.

\section{DMD-use patterns}

Nearly half of all DMD users with MS were new users, ie, they had not received any DMD prescription in the 2 years before cohort entry (Table 2). The highest proportion of new users was found for glatiramer acetate $(52.3 \%)$ and the lowest for immunoglobulins (32.3\%) and azathioprine (29.2\%); $41 \%$ of natalizumab and $51.3 \%$ of fingolimod users did not receive any DMD prescription in the 2 years before treatment initiation. Overall, only $5.0 \%$ were treated with two or more DMDs before cohort entry, while this was more often seen in users of fingolimod $(22.6 \%)$ and natalizumab (20.6\%).

A large proportion of MS patients was adherent to DMD treatment during follow-up (continuous single users, 42.4\%), followed by the patient group interrupting treatment with the index DMD for $>182$ days (interrupters). Switch of DMD treatment was less frequent (11.9\%), and only 5.6\% of all DMD users discontinued treatment. For individual DMDs, treatment discontinuation was most common in users of natalizumab (7.5\%) and IFN $\beta_{1 b}$ (7.0\%). Similarly, treatment switch was most often observed in users of natalizumab and IFN $\beta_{1 b}(15.4 \%$ and $18.3 \%$, respectively). Most MS patients switched to glatiramer acetate $(2.9 \%)$, followed by $\operatorname{IFN} \beta_{1 \mathrm{a}}(2.8 \%)$ and natalizumab (2.6\%).

\section{Incidence of adverse events}

The cohort for analysis of adverse events comprised 9,045 new users, of whom 5,124 were new users of IFN $\beta_{1 \text { a }}$ $(56.7 \%), 3,467$ of glatiramer acetate $(38.3 \%), 324$ of natalizumab (3.6\%), and 130 of fingolimod (1.4\%). In general, the number of observed adverse events under current treatment was low for all DMDs, especially for natalizumab and fingolimod (Table 3). The most frequent adverse event among new users all four DMDs combined was hospitalization for depression, with 54 cases $(0.6 \%)$, followed by any infectious disease, with 41 cases $(0.5 \%)$ and any malignancy, with 28 cases $(0.3 \%)$. The incidence rate of all adverse events did not significantly differ across different DMDs. In the sensitivity analysis without censoring at treatment discontinuation or switch, the number of adverse events was slightly higher. The incidence of hospitalization for any infectious disease was more than tripled for natalizumab, with $1,541.5$ per 100,000 person-years $(95 \%$ 


\begin{tabular}{|c|c|c|c|c|c|}
\hline 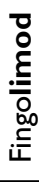 & $\stackrel{\text { ڤ̊ }}{\sim}$ & 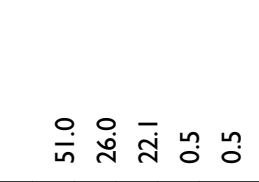 & 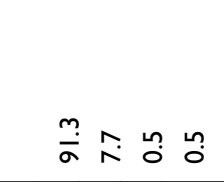 & 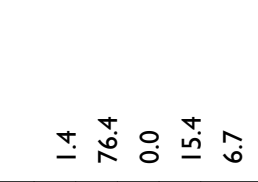 & 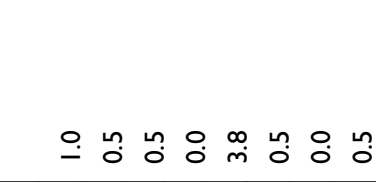 \\
\hline 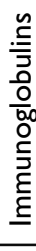 & 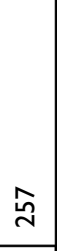 & 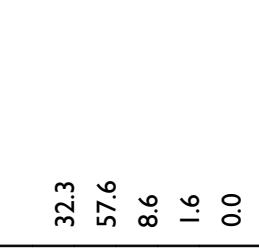 & 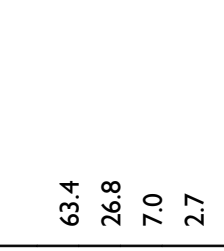 & 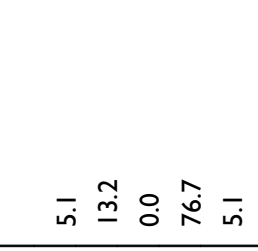 & 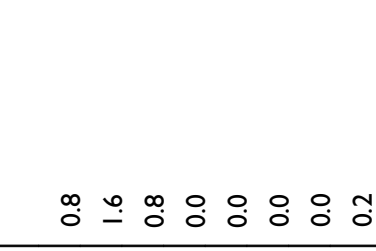 \\
\hline 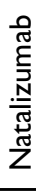 & 2 & 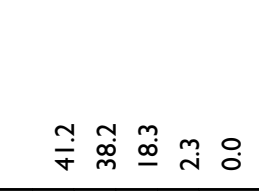 & 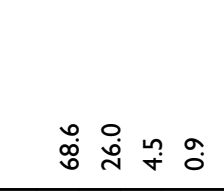 & 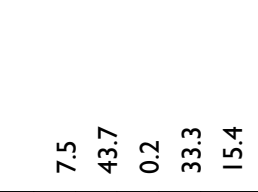 & 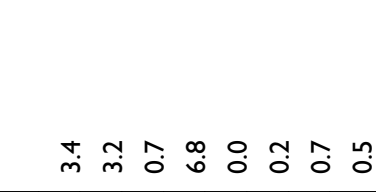 \\
\hline 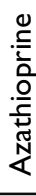 & ڤ & 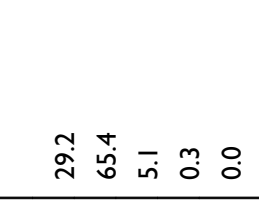 & $\bar{\infty} \underset{\dot{m}}{\stackrel{m}{m}} \hat{m} \stackrel{a}{0}$ & 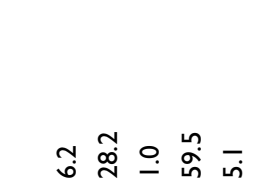 & ㅇ․ \\
\hline$\sum_{\underline{\underline{Z}}}^{\underline{n}}$ & $\stackrel{\substack{\infty \\
\sim}}{\sim}$ & 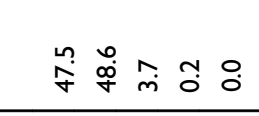 & 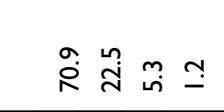 & 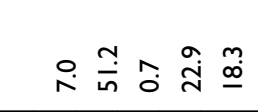 & 奋 \\
\hline 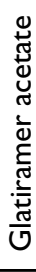 & $\begin{array}{l}\text { 离 } \\
\vdots \\
+\end{array}$ & 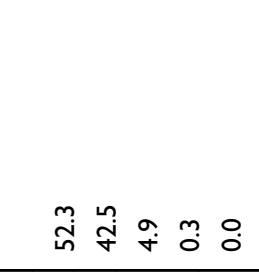 & 官 & 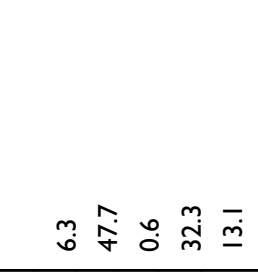 & $\stackrel{\circ}{\circ} \stackrel{\circ}{i} \bar{i} \bar{i} \hat{i} \stackrel{m}{0} \sigma_{0} \overline{0}$ \\
\hline$\overbrace{\underline{\underline{Z}}}^{\underline{\sigma}}$ & $\underset{\hat{0}}{N}$ & 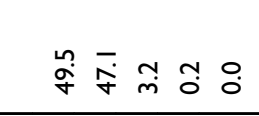 & $\stackrel{n}{N} \stackrel{n}{=} \stackrel{+}{*} \stackrel{\infty}{0}$ & 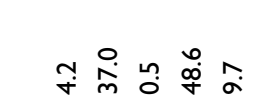 & 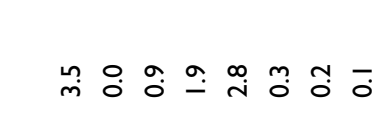 \\
\hline 苛 & 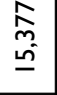 & 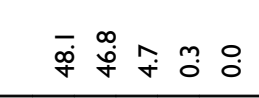 & $\stackrel{\circ}{\stackrel{0}{\infty}} \stackrel{\text { ก }}{+}$ 。 & 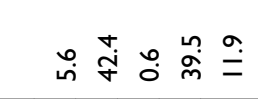 & 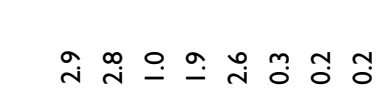 \\
\hline & 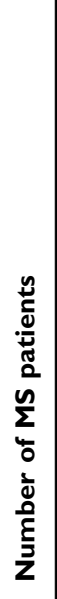 & 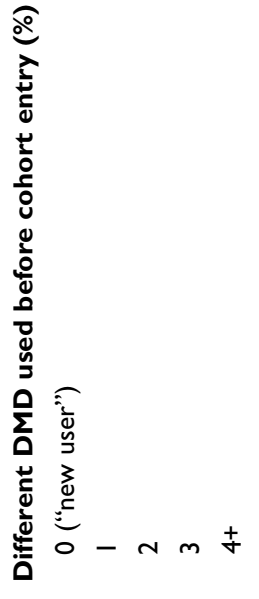 & 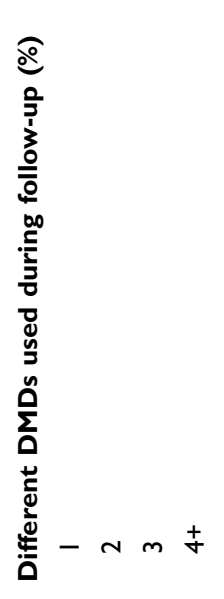 & 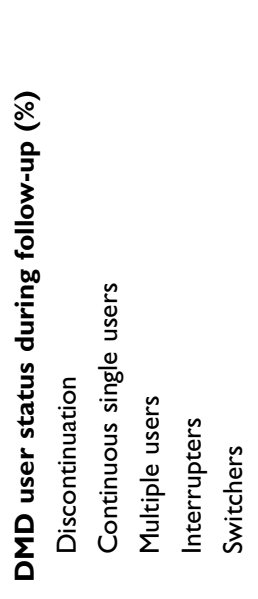 & 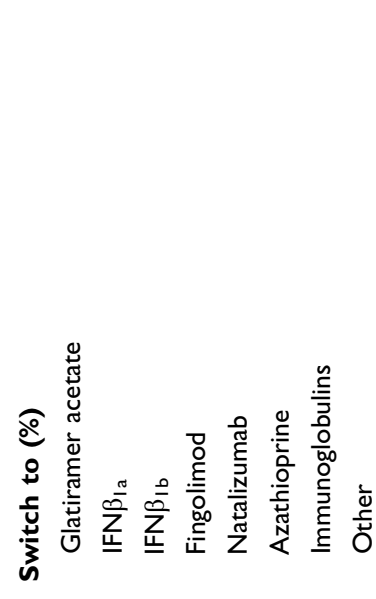 \\
\hline
\end{tabular}




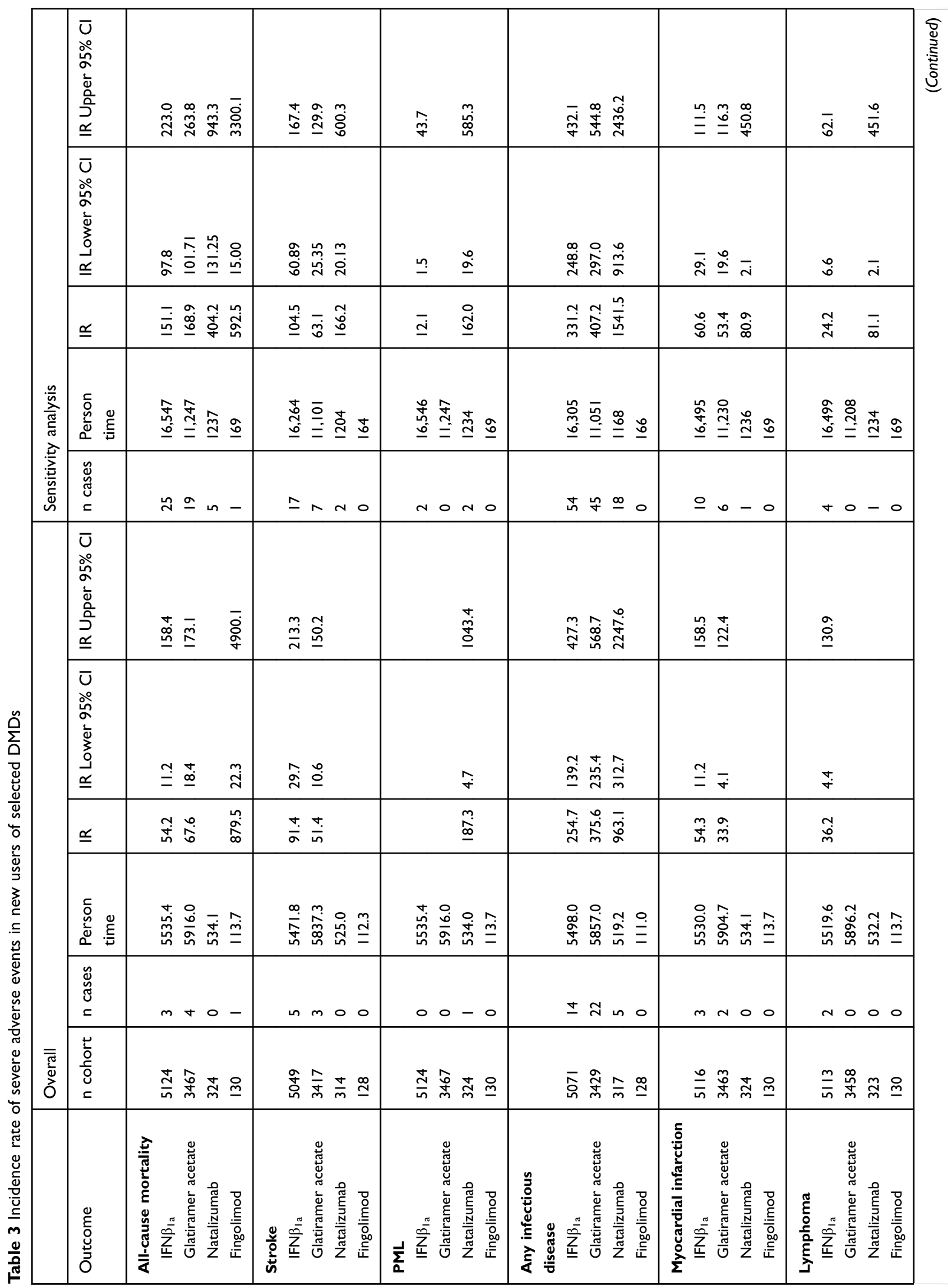




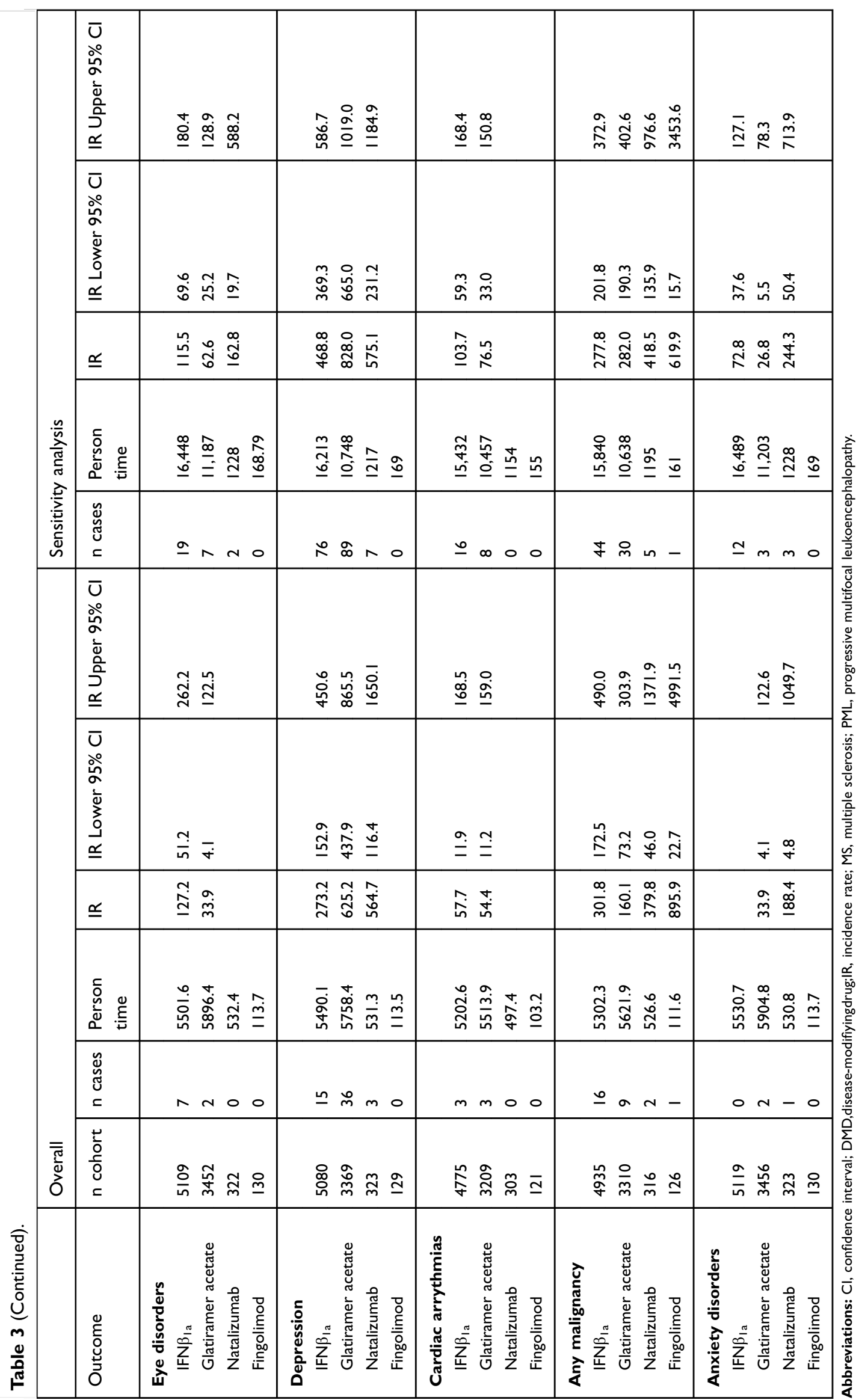


CI 913.6-2,436.2) compared to IFN $\beta_{1 \mathrm{a}}$, with $331.2(95 \%$ CI 248.8-432.1) and glatiramer acetate, with 407.2 (95\% CI 297.0-544.8). In addition, the incidence of depression was nearly doubled for glatiramer acetate, with 828.0 $(95 \%$ CI $665.0-1,019.0)$ compared to IFN $\beta_{1 \text { a }}$, with 468.8 (95\% CI 369.3-586.7).

\section{Discussion}

In this large cohort study based on German claims data, we have described the clinical characteristics and drug-use patterns of 15,377 MS patients using DMDs and estimated the incidence of severe adverse events in new DMD users.

Among the most frequently observed comorbidities were two psychiatric conditions: depression and anxiety disorders. Variations for some comorbidities, eg, bladder dysfunction or muscle spasticity, indicated that natalizumab, fingolimod, and immunoglobulins were usedprimarilyas second-line treatment in patients with higher disease activity. Users of azathioprine with MS had the highest prevalence of comorbidities. Although this may at least partly be attributed to a higher mean age, our results show that azathioprine is still frequently used as an alternative drug in patients with higher disease activity or in cases of nonresponse to other DMDs. In addition, the high prevalence of inflammatory bowel disease and rheumatic arthritis/collagen vascular disease indicates frequent use of azathioprine in MS patients with coexisting autoimmune disease. ${ }^{27,28}$ In comparison to other studies, most comorbidities in our study had higher prevalence than the aggregated results of a meta-analysis by Marrie et al. ${ }^{29}$ However, the results varied widely in that study depending on region, study population, and study design, and none assessed comorbidities based on drug level.

The overall rate of MS relapses per patient per year in our study was similar for all DMD users, with the exception of patients receiving natalizumab or immunoglobulins. The overall rate in our study is consistent with the results Tremlett et al, ${ }^{30}$ who followed relapsing-remitting MS patients and found that slightly lower overall annual relapse rates depended strongly on age and sex. For MS patients treated with natalizumab and fingolimod, lower annual rates $^{31-33}$ than in our study have been reported. However, these studies differed from ours in terms of follow-up duration and the proportion of new DMD users.

The most frequently prescribed comedications were NSAIDs and antidepressants, which is similar to findings of a Dutch health care claim-data study. ${ }^{34}$ In our study, NSAIDs were most often coprescribed in patients using fingolimod or interferons. The use of NSAIDs in these patients may be indicated for symptomatic treatment of common side effects, such as headache and back pain, ${ }^{35-37}$ or for mitigation of flulike side effects associated with the use of interferons. ${ }^{38,39}$ Users of natalizumab and fingolimod more frequently receive plasmapheresis, immunoadsorption, methylprednisolone, and fampridine, again emphasizing their use in patients with higher disease activity.

\section{Drug-use patterns for DMDs}

Almost half of all DMD users with MS were new users without any DMD prescription in the 2 years before cohort entry. Although natalizumab and fingolimod are considered second-line treatment, roughly half of all users for the two did not receive any DMD prescription in the 2 years before treatment initiation. It remains unclear if these patients were treated first-line due to high disease activity or if pharmacological treatment was interrupted for more than 2 years, eg, due to nonresponse or remission of MS, and then restarted on a more efficacious DMD. Natalizumab and fingolimod revealed the highest proportion of patients previously treated with two or more DMDs, ie, second- or third-line treatment.

In general, the number of MS patients with treatment discontinuation was low, despite the long maximum observation period of 8 years. Nevertheless, we observed that $<50 \%$ of the MS patients were treatedcontinuouslywith the same DMD over time. In another German study based on claims data between 2001 and 2009, similar results were found, with only $30 \%-40 \%$ of MS patients adherent to DMDs within 2 years after initiation. ${ }^{24}$ Interestingly, we found that nearly $40 \%$ of MS patients interrupted treatment with that drug for $>6$ months. Potential reasons for treatment interruptions may include adverse events or the wish for children/pregnancies, and should be evaluated in further studies. The proportion of switchers to other DMDs was relatively low, and highest for IFN $\beta_{1 \mathrm{~b}}$ and natalizumab. Again, reasons for DMD switch, eg, adverse events or nonresponse, should be investigated in further studies.

\section{Incidence rate of adverse events}

The primary analysis of severe adverse events in new users of fingolimod, natalizumab, glatiramer acetate, and IFN $\beta_{1 \mathrm{a}}$ did not reveal significant differences in incidence rates among individual DMDs. In general, the observed absolute number of adverse events was low, especially for those with low background incidence in the overall population, such as lymphoma, stroke or PML, as well as for natalizumab and 
fingolimod, as newer DMDs with small samples. This finding is of particular clinical relevance, since discontinuation of the latter drugs due to safety concerns has been associated with severe rebound effects that have to be balanced against the possible risk of severe adverse events. ${ }^{40,41}$ In the sensitivity analysis without censoring at treatment discontinuation or switch, the absolute number of adverse events was slightly higher. We found a more than tripled increased incidence of hospitalization for any infectious disease in users of natalizumab compared to users of IFN $\beta_{1 \mathrm{a}}$ and glatiramer acetate. Increased risk for infection-related physician claims under natalizumab treatment has also been reported in a study based on administrative data from Canada, in which no increased risk was observed for first-line therapies, such as interferons or glatiramer acetate. ${ }^{42}$ The hospitalization rate for depression was nearly doubled for glatiramer acetate compared to IFN $\beta_{1 \mathrm{a}}$. Although the prevalence of depression in users of glatiramer acetate was slightly higher in the baseline period and our risk estimates were unadjusted, this observation requires evaluation. In previous studies, only IFN $\beta$ has been associated with depression in patients with MS. $^{43,44}$

\section{Strengths and limitations}

The main strength of this study is the size and representativeness of GePaRD, which covers approximately 20 million insured members of SHI throughout Germany per data year. Determination of exposure based on pharmacy dispensing data is considered the gold standard, as recall bias can be ruled out, even for patients suffering from severe diseases, such as MS and information is regarded as precise in time, product (including brand), and dose. ${ }^{45}$ As the DMDs examined are available on prescription only, ascertainment of exposure is assumed to be complete for most of the drugs.

A limitation of this study is that inpatient treatment with DMDs in GePaRD can be assessedonlyfor natalizumab, rituximab, and alemtuzumab. If patients are hospitalized for longer periods receiving in-hospital DMD treatment, this might result in underestimation of exposure and biased druguse patterns. Another limitation is that rituximab, alemtuzumab, cyclophosphamide, and mitoxantrone are compounding drugs that were partially reimbursed via a generic central pharmaceutical number during the study period. This did not allow a distinction among individual drugs, ie, exposure to these drugs will additionally have been underestimated. Further, GePaRD contains information on all outpatient drug dispensations; however, information on prescribed daily doses cannot be directly ascertained. Therefore, we used an algorithm to estimate the duration of treatment to allow for dosage variation and possible nonadherence. As our study did not include a review of individual patient files to confirm the occurrence of outcomes, which is generally not feasible in GePaRD for data-protection reasons, case validation was not possible and misclassification of MS and adverse events cannot be ruled out. For this reason, onlymainhospital-discharge diagnoses were used for outcome definitions, which were assumed to provide the most valid information. Misclassification of MS cases is assumed to be rare, since our case definition required a diagnosis accompanied by an MS-specific treatment. As a general limitation, data were availableonlyuntil 2013, ie, the number of users and severe adverse events of novel DMDs, such as natalizumab, and fingolimod was low and recently approved drugs, such as teriflunomide, dimethyl fumarate, and cladribine could not be examined.

\section{Conclusion}

Our study suggests a high burden of comorbidities in MS patients using DMDs, especially with respect to psychiatric and autoimmune diseases. Treatment discontinuation with DMDs and treatment switch were rare, but only $42 \%$ received continuous DMD treatment. Reasons for the unexpected high frequency of DMD-treatment interruption have to be evaluated in further studies. Active safety monitoring of new DMDs based on claims data requires large data sets to detect rare adverse events, such as PML, and availability of up-to-date data.

\section{Acknowledgments}

This study was in part funded through the REGIMS Register within the German Competence Network of Multiple Sclerosis ("Kompetenznetz Multiple Sklerose", KKNMS), which is funded by the German Ministry of Education and Research ("Bundesministerium für Bildung und Forschung", BMBF, 01GI0907), and cofunded by Biogen Germany. We would like to thank Sandra Ulrich and Jan Thies Soller, who analyzed the data. The authors would like to thank all statutory health-insurance providers that supplied data for this study, namely AOK Bremen/Bremerhaven, the DAK Gesundheit, HKK Krankenkasse, and Die Techniker (TK).

\section{Disclosure}

Mrs Alexandra Simbrich, Dr Jasmine Thibaut, and Professor Klaus Berger report grants from the 
German Ministry of Education and Research and Biogen Germany, during the conduct of the study. The authors report no other conflicts of interest in this work.

\section{References}

1. Compston A, Coles A. Multiple sclerosis. Lancet. 2008;372 (9648):1502-1517.

2. Schmedt N, Khil L, Berger K, Riedel O. Incidence of multiple sclerosis in germany: a cohort study applying different case definitions based on claims data. Neuroepidemiology. 2017;49(3-4):91-98.

3. Kingwell E, Marriott JJ, Jetté N, et al. Incidence and prevalence of multiple sclerosis in Europe: a systematic review. BMC Neurol. 2013;13:128.

4. Torkildsen Ø, Myhr KM, Bø L. Disease-modifying treatments for multiple sclerosis - a review of approved medications. Eur J Neurol. 2016;23(Suppl 1):18-27.

5. Montalban X, Gold R, Thompson AJ, et al. ECTRIMS/EAN guideline on the pharmacological treatment of people with multiple sclerosis. Mult Scler. 2018;24(2):96-120.

6. Kalincik T, Brown JWL, Robertson N, et al. Treatment effectiveness of alemtuzumab compared with natalizumab, fingolimod, and interferon beta in relapsing-remitting multiple sclerosis: a cohort study. Lancet Neurol. 2017;16(4):271-281.

7. Druart C, El Sankari S, van Pesch V. Long-term safety and real-world effectiveness of fingolimod in relapsing multiple sclerosis. Patient Relat Outcome Meas. 2017;9:1-10.

8. Dörr J, Paul F. The transition from first-line to second-line therapy in multiple sclerosis. Curr Treat Options Neurol. 2015;17(6):354.

9. Ziemssen T, De Stefano N, Sormani MP, Van Wijmeersch B, Wiendl H, Kieseier BC. Optimizing therapy early in multiple sclerosis: an evidence-based view. Mult Scler Relat Disord. 2015;4(5):460-469.

10. Sørensen PS. Balancing the benefits and risks of disease-modifying therapy in patients with multiple sclerosis. J Neurol Sci. 2011;311(Suppl 1): S29-34.

11. Bloomgren G, Richman S, Hotermans C. Risk of natalizumab-associated progressive multifocal leukoencephalopathy. N Engl J Med. 2012;366(20):1870-1880.

12. Berger JR, Cree BA, Greenberg B, et al. Progressive multifocal leukoencephalopathy after fingolimod treatment. Neurology. 2018;90(20):e1815-e1821.

13. Moll NM, Rietsch AM, Ransohoff AJ, et al. Cortical demyelination in PML and MS: similarities and differences. Neurology. 2008;70 (5):336-343.

14. Fox RJ, Cutter G. Long-term registries: answering tough questions with big data? Neurol Clin Pract. 2016;6(2):97-99.

15. Bezzini D, Battaglia MA. Multiple sclerosis epidemiology in Europe. Adv Exp Med Biol. 2017;958:141-159.

16. Stein JD, Lum F, Lee PP, Rich WL, Coleman AL. Use of health care claims data to study patients with ophthalmologic conditions. Ophthalmology. 2014;121(5):1134-1141.

17. Ziemssen T, Lang M, Tackenberg B, et al. Clinical and demographic profile of patients receiving fingolimod in clinical practice in Germany and the benefit-risk profile of fingolimod after 1 year of treatment: initial results from the observational, noninterventional study PANGAEA. Neurotherapeutics. 2018;15(1):190-199.

18. Kaufmann M, Haase R, Proschmann U, Ziemssen T, Akgun K. Real world lab data: patterns of lymphocyte counts in fingolimod treated patients. Front Immunol. 2018;9:2669.

19. Kaufmann M, Haase R, Proschmann U, Ziemssen T, Akgun K. Realworld lab data in natalizumab treated multiple sclerosis patients up to 6 years long-term follow up. Front Immunol. 2018;9:1071.
20. Alsop J, Medin J, Cornelissen C, Vormfelde SV, Ziemssen T. Two studies in one: A propensity-score-matched comparison of fingolimod versus interferons and glatiramer acetate using real-world data from the independent German studies, PANGAEA and PEARL. PLoS One. 2017;12(5):e0173353.

21. Smith MY, Sabido-Espin M, Trochanov A, et al. Postmarketing safety profile of subcutaneous interferon beta-1a given 3 times weekly: a retrospective administrative claims analysis. $J$ Manag Care Spec Pharm. 2015;21(8):650-660.

22. Katsarava Z, Ehlken B, Limmroth V, et al. Adherence and cost in multiple sclerosis patients treated with IM IFN beta-1a: impact of the CARE patient management program. BMC Neurol. 2015;15:170.

23. Zettl UK, Bauer-Steinhusen U, Glaser $T$, et al. Adherence to long-term interferon beta- $1 \mathrm{~b}$ injection therapy in patients with multiple sclerosis using an electronic diary. Adv Ther. 2016;33 (5):834-847.

24. Hansen K, Schussel K, Kieble M, et al. Adherence to disease modifying drugs among patients with multiple sclerosis in Germany: a retrospective cohort study. PLoS One. 2015;10(7):e0133279.

25. Garbe E, Suling M, Kloss S, Lindemann C, Schmid U. Linkage of mother-baby pairs in the German pharmacoepidemiological research database. Pharmacoepidemiol Drug Saf. 2011;20(3):258-264.

26. Pigeot I, Ahrens W. Establishment of a pharmacoepidemiological database in Germany: methodological potential, scientific value and practical limitations. Pharmacoepidemiol Drug Saf. 2008;17(3):215-223.

27. Kozuch PL, Hanauer SB. Treatment of inflammatory bowel disease: A review of medical therapy. World J Gastroenterol. 2008;14 (3):354.

28. Fraser AG, Orchard TR, Jewell DP. The efficacy of azathioprine for the treatment of inflammatory bowel disease: a 30 year review. Gut. 2002;50(4):485-489.

29. Marrie RA, Cohen J, Stuve O, et al. A systematic review of the incidence and prevalence of comorbidity in multiple sclerosis: overview. Mult Scler. 2015;21(3):263-281.

30. Tremlett H, Zhao Y, Joseph J, Devonshire V; UBCMS Clinic Neurologists. Relapses in multiple sclerosis are age- and time-dependent. $\quad J$ Neurol Neurosurg Psychiatry. 2008;79 (12):1368-1374.

31. O'Connor P, Goodman A, Kappos L, et al. Long-term safety and effectiveness of natalizumab redosing and treatment in the STRATA MS Study. Neurology. 2014;83(1):78-86.

32. Polman $\mathrm{CH}$, O'Connor PW, Havrdova E, et al. A randomized, placebo-controlled trial of natalizumab for relapsing multiple sclerosis. N Engl J Med. 2006;354(9):899-910.

33. Derfuss T, Ontaneda D, Nicholas J, Meng X, Hawker K. Relapse rates in patients with multiple sclerosis treated with fingolimod: subgroup analyses of pooled data from three phase 3 trials. Mult Scler Relat Disord. 2016;8:124-130.

34. Buijs S, Krol M, de Voer G. Healthcare utilization and costs of multiple sclerosis patients in the Netherlands: a healthcare claims database study. J Comp Eff Res. 2018;7(5):453-462.

35. Cohen JA, Barkhof F, Comi G, et al. Oral fingolimod or intramuscular interferon for relapsing multiple sclerosis. $N$ Engl $J$ Med. 2010;362(5):402-415.

36. Kappos L, Radue EW, O’Connor P, et al. A placebo-controlled trial of oral fingolimod in relapsing multiple sclerosis. $N$ Engl $\mathrm{J} \mathrm{Med}$. 2010;362(5):387-401.

37. Calabresi PA, Radue EW, Goodin D, et al. Safety and efficacy of fingolimod in patients with relapsing-remitting multiple sclerosis (FREEDOMS II): a double-blind, randomised, placebo-controlled, phase 3 trial. Lancet Neurol. 2014;13(6):545-556.

38. Río J, Nos C, Bonaventura I, et al. Corticosteroids, ibuprofen, and acetaminophen for IFNbeta-1a flu symptoms in MS: a randomized trial. Neurology. 2004;63(3):525-528. 
39. Reeß J, Haas J, Gabriel K, Fuhlrott A, Fiola M. Both paracetamol and ibuprofen are equally effective in managing flu-like symptoms in relapsing-remitting multiple sclerosis patients during interferon beta-1a (AVONEX®) therapy. Mult Scler. 2002;8(1):15-18.

40. Clerico M, Schiavetti I, De Mercanti SF, et al. Treatment of relapsing-remitting multiple sclerosis after 24 doses of natalizumab: evidence from an Italian spontaneous, prospective, and observational study (the TY-STOP Study). JAMA Neurol. 2014;71(8):954-960.

41. Hatcher SE, Waubant E, Nourbakhsh B, Crabtree-Hartman E, Graves JS. Rebound syndrome in patients with multiple sclerosis after cessation of fingolimod treatment. JAMA Neurol. 2016;73(7):790-794.

42. Wijnands JMA, Zhu F, Kingwell E, et al. Disease-modifying drugs for multiple sclerosis and infection risk: a cohort study. $J$ Neurol Neurosurg Psychiatry. 2018;89(10):1050-1056.
43. Alba Pale L, Leon Caballero J, Samso Buxareu B, Salgado Serrano P, Perez Sola V. Systematic review of depression in patients with multiple sclerosis and its relationship to interferon $\beta$ treatment. Mult Scler Relat Disord. 2017;17:138-143.

44. de Jong HJI, Kingwell E, Shirani A, et al. Evaluating the safety of beta-interferons in MS: A series of nested case-control studies. Neurology. 2017;88(24):2310-2320.

45. Schneeweiss S, Avorn J. A review of uses of health care utilization databases for epidemiologic research on therapeutics. $J$ Clin Epidemiol. 2005;58(4):323-337. 


\section{Supplementary materials}

Table SI Definition of comorbidities and outcomes

\begin{tabular}{|c|c|}
\hline Entity of Disease & Diagnoses (ICD-I0-GM) \\
\hline Myocardial infarction & $121 x, 122 x$ \\
\hline Other coronary heart disease & $120 x, 123 x-125 x$ \\
\hline $\begin{array}{l}\text { Congestive heart failure and } \\
\text { cardiomyopathy }\end{array}$ & $1099,1110,1130,1132,1255,142 x, 143 x, 150 x, 1971$ \\
\hline Hemophagocytic syndrome & D76I \\
\hline Arterioventricular block/bradycardia & I440-I443, R00I \\
\hline $\begin{array}{l}\text { Cardiac arrhythmias and conduction } \\
\text { disorders }\end{array}$ & I44x, I45x, I48x, 1460, 1469, I47x-149x, R000, R00I, R008, T82I, Z450, Z950 \\
\hline Hypertension & $110 x-113 x, 115 x$ \\
\hline Stroke & $160 x-164$ \\
\hline Cerebrovascular disease & G45x, G46x, H340, 165x-169x \\
\hline Chronic pulmonary disease & $J 40 x-J 47 x, J 60 x-J 67 x, J 684, J 70 I, J 703$ \\
\hline $\begin{array}{l}\text { Rheumatic arthritis/collagen vascular } \\
\text { disease }\end{array}$ & $\begin{array}{l}\text { L940, L94I, L942, M05x, M06x, M08x, MI20, MI23, M30x, M3I0-M3I3, M32x-M35x, M45x, M46I, M468, } \\
\text { M469 }\end{array}$ \\
\hline Inflammatory bowel disease & $\mathrm{K} 50 \mathrm{x}-\mathrm{K} 52 \mathrm{x}$ \\
\hline Mild liver disease & K700, K70I-K703, K709, K7I3-K7I5, K7I7, K73x, K74x, K760,K762-K764, K768, K769, Z944 \\
\hline Moderate/severe liver disease & I850, I864, 1982, K704, K7II, K72I, K729, K765-K767 \\
\hline Renal disease & $\begin{array}{l}\text { II 20, II II, N032, N033, N034, N035, N036, N037, N052, N053, N054, N055, N056, N057, NI8x, NI9x, } \\
\text { N250, Z49x, Z940, Z992 }\end{array}$ \\
\hline Epilepsy & G40x, G4Ix, \\
\hline Migraine & G43x \\
\hline Depression & $F 204, F 3|3-F 3| 5, F 32 x, F 33 x, F 34 I, F 4 I 2, F 432$ \\
\hline Anxiety disorders & $\mathrm{F} 4 \mathrm{Ix}$ \\
\hline Diabetes & EI0x-EI4x \\
\hline Hyperthyroidism/Hypothyroidism & E00x-E03x,E05x, E890 \\
\hline Lymphoma & $C 81 x-C 85 x$ \\
\hline Any malignancy & C00x-C97x \\
\hline Blood dyscrasias & D59x, D60x-D64x, D693-D696, D70x, D72x \\
\hline Weight loss or weight gain & R634, R635 \\
\hline Alcohol abuse & FI0x, G62I, I426, K292, K70x, T5Ix, Z502 \\
\hline Drug abuse & FIIx-FI6x, FI8x, FI9x, \\
\hline Eye disorders & $\mathrm{H} 25 \mathrm{x}, \mathrm{H} 26 \mathrm{x}, \mathrm{H} 35 \mathrm{x}, \mathrm{H} 40 \mathrm{x}, \mathrm{H} 42 \mathrm{x}, \mathrm{H} 532$ \\
\hline Alopecia & L63x-L65x \\
\hline Arthralgia, muscle spasticity & M255 \\
\hline $\begin{array}{l}\text { Muscle spasticity other neurological } \\
\text { symptoms }\end{array}$ & $R 25 x-R 27 x$ \\
\hline Urinary tract infection & N390 \\
\hline HIVIAIDS & B20-B24x \\
\hline Hepatitis B or C & $\mathrm{B}|6 \mathrm{x}, \mathrm{B}| 7|, \mathrm{~B}| 80-\mathrm{B} \mid 82$ \\
\hline
\end{tabular}


Table SI (Continued).

\begin{tabular}{|l|l|}
\hline Entity of Disease & Diagnoses (ICD- I O-GM) \\
\hline Herpetic infections & B00x, B02x \\
Progressive multifocal & A8I2 \\
leukoencephalopathy & B35x-B49x \\
Mycoses & J100, JII0, JI2x-J16x, J18x, J85I \\
Pneumonia & A15x-A19x \\
Tuberculosis & A00x-B99x \\
Other infectious diseases & K85x, K860, K86I \\
Pancreatitis & F480, R53 \\
Fatigue & N3Ix, N328, N393, N394, R32, R33, R39I \\
Bladder dysfunction & F522, N484 \\
Sexual dysfunction & K590-K592, RI5 \\
Bowel dysfunction & \\
\hline
\end{tabular}

Table S2 Definition of comedication

\begin{tabular}{|c|c|c|}
\hline Drug class & ATC Code & OPS Code \\
\hline Insulin & AIOA & \\
\hline Antidiabetic drugs & $\mathrm{AIOB}$ & \\
\hline Antithrombotic drugs & $\mathrm{BOIA}$ & \\
\hline Anti-arrhythmic drugs & COIB & \\
\hline Antihypertensive drugs & $\mathrm{CO2}$ & \\
\hline Glucocorticoids & H02AB (excl. H02AB04) & \\
\hline Methylprednisolone (parenteral) & $\mathrm{H} 02 \mathrm{AB} 04$ & \\
\hline Opioids & N02A & \\
\hline Antiepileptic drugs & N03 & \\
\hline Anti-dementia drugs & N06D & \\
\hline Nonsteroidal anti-inflammatory drugs & MOIA & \\
\hline Muscle relaxants & M03 & \\
\hline Antidepressants & N06A & \\
\hline Anxiolytics & N05B & \\
\hline Hypnotics and sedatives & N05C & \\
\hline Drugs for urinary frequency and incontinence & G04BD & \\
\hline Drugs used in erectile dysfunction & G04BE & \\
\hline Fampridin & N07XX07 & \\
\hline Other interventions & ATC Code & OPS Code \\
\hline Plasmapheresis & & $8820 x$ \\
\hline Immunoadsorption & & $8821 x$ \\
\hline
\end{tabular}




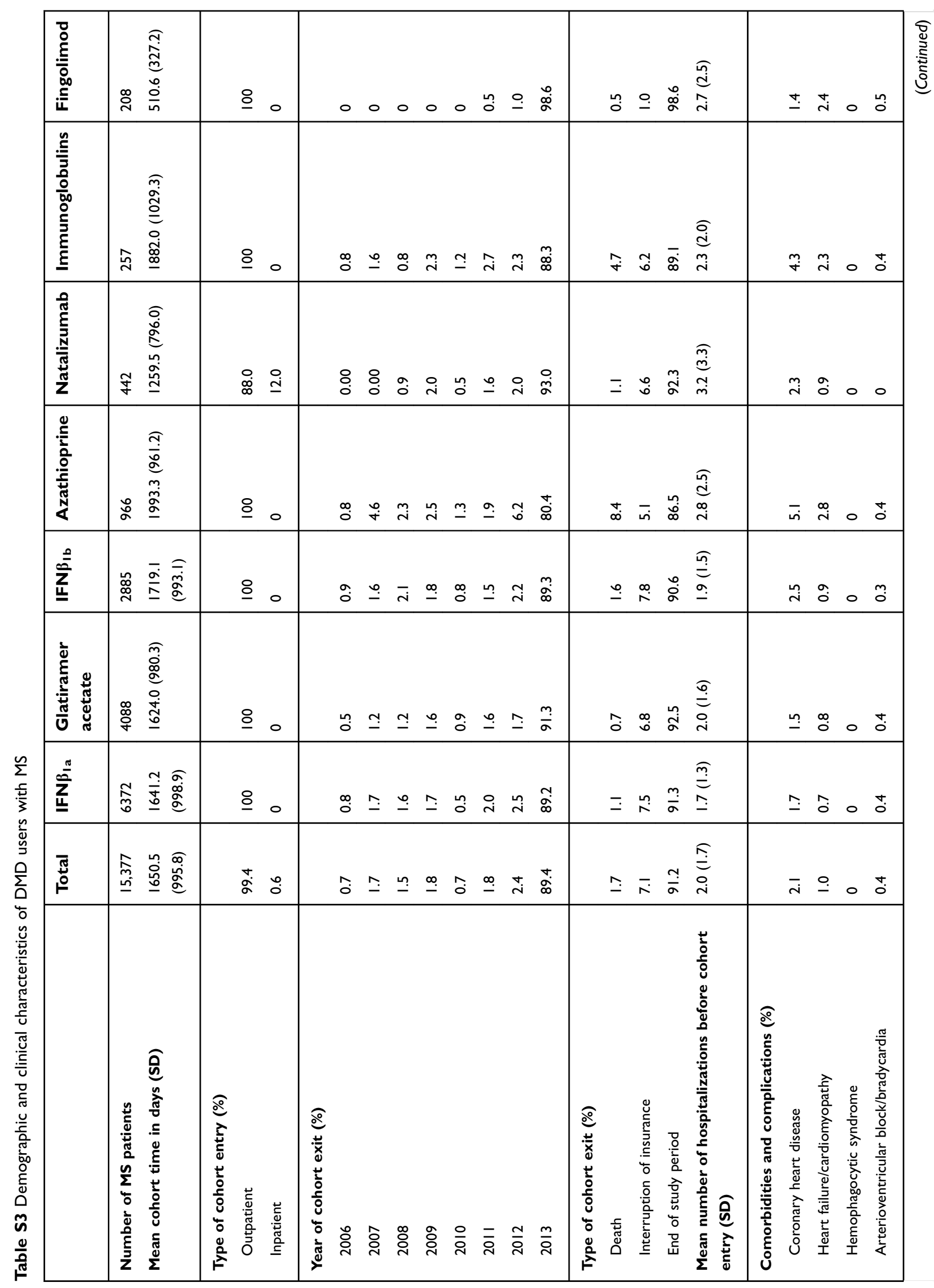




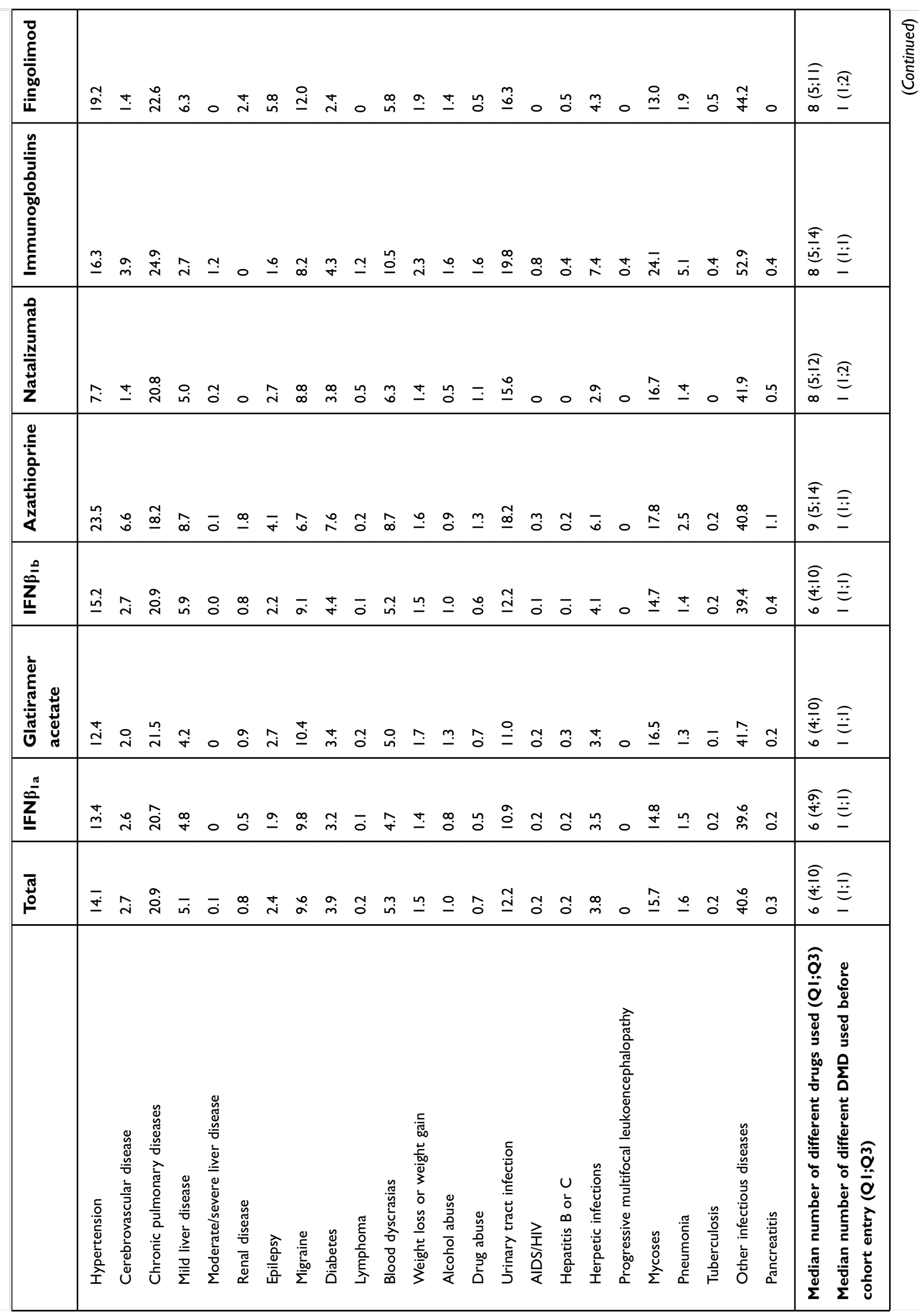




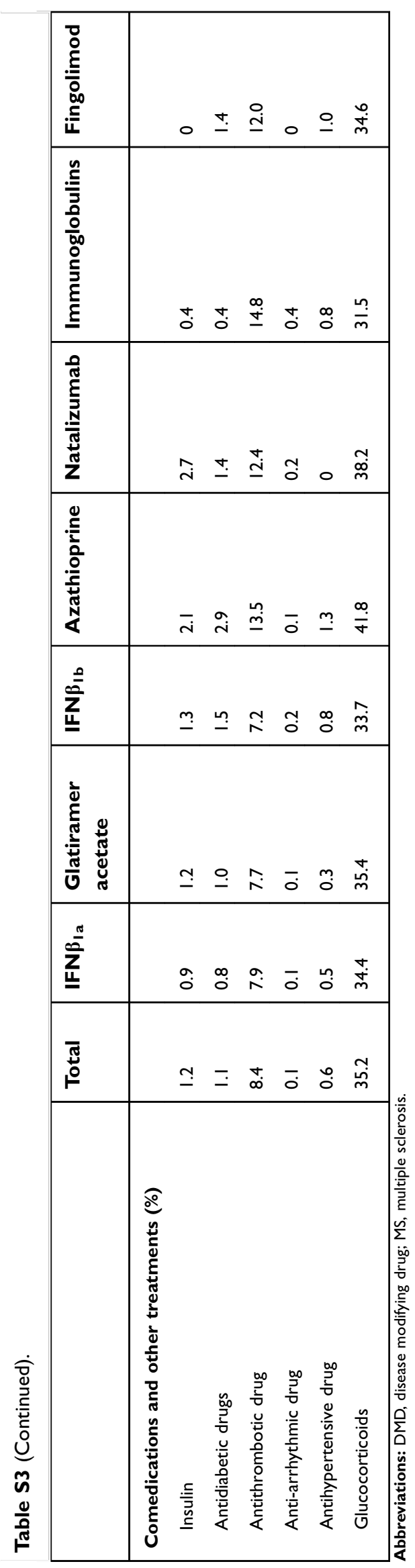




\section{Publish your work in this journal}

Neuropsychiatric Disease and Treatment is an international, peerreviewed journal of clinical therapeutics and pharmacology focusing on concise rapid reporting of clinical or pre-clinical studies on a range of neuropsychiatric and neurological disorders. This journal is indexed on PubMed Central, the 'PsycINFO' database and CAS, and is the official journal of The International Neuropsychiatric Association (INA). The manuscript management system is completely online and includes a very quick and fair peer-review system, which is all easy to use. Visit http://www.dovepress.com/testimonials.php to read real quotes from published authors.

Submit your manuscript here: https://www.dovepress.com/neuropsychiatric-disease-and-treatment-journal 